\title{
Elicitation of salt stress-tolerant mutants in bread wheat (Triticum aestivum L.) by using gamma radiation
}

\author{
Almoataz Bellah Ali El-Mouhamady ${ }^{*}$ and Hayam Fouad Ibrahim
}

\begin{abstract}
Background: Given the strategic importance of wheat being the staple food for the vast majority of people, it was necessary to know reasons for the contraction and decline of its area globally and consequently its lower yield. Among the most important of these problems is the problem of a high level of salinity in both soil and irrigation water coming at the forefront of environmental challenges that hinder its production process at the local and global levels. Therefore, the genetic improvement of wheat for salinity tolerance was one of the most important priorities of this investigation.
\end{abstract}

Results: The seven wheat accessions (Sakha 8 and its six M5 derived mutants) succeeded in drawing unique cases of salinity tolerance and were excellent especially mutants $1,2,3$, and 5 . The rest genotypes were coming in the second rank for this purpose and were very good in this regard. The promising wheat genotypes which recorded high salinity tolerance in the recent investigation exhibited also high genetic stability. This fact was proved after estimating some agro-morphological and physiological traits related to salinity tolerance based on evaluating some important genetic parameters besides salinity tolerance indices under stress experiment compared to the control treatment within two seasons. Data evaluated of expected genetic advance (GA) based on 5\% selection proved that all values calculated during the two seasons under both treatments appeared low for all studied traits in this regard. However, it reflects the success of breeding for salinity tolerance in wheat using mutations but in relative terms. Molecular marker analysis profile using the six ISSR primers exhibited a total of 173 markers, 12 of them were monomorphic, while that 161 bands appeared polymorphic included 56 unique bands or positive markers and 7 negative markers with $93.06 \%$ (polymorphism).

Conclusion: The original wheat variety (Sakha 8) and its six M5 derived mutants exhibited high tolerance of salinity stress in all studied traits based on all genetic parameters and salinity tolerance indices calculated for both seasons under salinity treatment compared to the normal conditions. DNA fingerprinting analysis as well for the six wheat mutants besides the local variety proved that these genotypes were recorded highly genetic differences among them.

Keywords: Wheat, Salinity tolerance, Gamma rays, Mutation, Genetic variation, Heritability, Expected genetic advance, ISSR markers, DNA fingerprinting

\footnotetext{
* Correspondence: moaatazelmohamady@gmail.com;

elmouhamady@yahoo.com

Genetics and Cytology Department, Genetic Engineering and Biotechnology

Research Division, National Research Centre, 33 El Buhouth ST, Dokki, Cairo

12622, Egypt
} 


\section{Background}

Wheat is one of the most important food crops over the centuries not only for humans, but also for animals and birds with the increasing of the global wheat consumption due to the growing population. At the present time, it is noted that the area and productivity of wheat in Egypt are subjected to many environmental challenges and constraints such as high level of soil salinity and irrigation water, water poverty, and high toxicity of heavy metals. In addition, various diseases and all these factors would reduce productivity. Particularly noteworthy in this context, the imminent danger resulting from increasing salinity level in soil and irrigation water because high salinity directly impedes on all vital processes necessary for growth and germination that cause a reduction in wheat productivity by 40 to $50 \%$. When we talk about the problem of water poverty and the decline in the share of water needed for agriculture in Egypt, it is noted that this will be in line with the rising of salinity level in soil especially in coastal land nearing from the seawater. Therefore, scientists have joined forces to solve this problem and reduce the risk of high salinity. This will do through traditional methods of plant breeding including a breeding program by mutations besides modern methods such as biotechnology for improving and developing new wheat accessions tolerant for salinity as well as keeping high yielding under this stress. Singh and Balyan (2009) studied induced mutations in bread wheat for improving plant height, grain quality, and some yield traits in Kharchia 65 cultivar using four levels of gamma rays $(10,20,30$, and $40 \mathrm{KR})$ in addition to the control. This investigation succeeds in generating 3 mutant progenies that may be fruitful and excellent for development and increasing yield traits. High limit of salinity or water stresses decreasing from 35 to $57 \%$ of the final yield of crops when drought stress is taken as $40-45 \%$ of soil normal water content (NWC: 100\%) (Balla et al. 2011). The improvement and depiction of anew TiLLING population in selected mutant wheat accessions were conducted by Chen et al. (2012). Results confirmed that this mutant population representatives are considering a fruitful and important new material for the wheat explore society and the use of this invert genetic differences will supply version allelic divergence for wheat amelioration and practical genomics. Heiba et al. (2016b) showed the impact of $0.3 \%$ of ethylmethane sulphonate (EMS) for the detection of mutation chances of DNA in 3 bread wheat entries using RAPD and ISSR primers. Results revealed that RAPD primers given a total of 57 fragments under the normal conditions where 27 of them were polymorphic besides 17 new amplicons observed after treating with (EMS), while the ratio of mutation induction by ISSR markers was $0.08 \%$ which generated 4 various new bands, respectively.
Genetic diversity in sodium azide induced wheat mutants through analyzing SSR primers was determined by Sen and Sarsu (2018). Results detected that SSR marker profiles generated total mean values of polymorphism rate (29.44\%), polymorphic information content (PIC; 0.82), marker index (MI; 1.95), and resolving power (Rp; 1.31) in 44 generation advanced wheat mutant lines which indicated that SSRs succeed to screen genetic diversity in sodium azide induced of the previous wheat mutant accessions. Sahoo et al. (2018) detected salinity stress tolerance in some wheat accessions which emphasized that it is difficult to rely solely on the genetic aspects to reduce risks of salinity on wheat crops. But, in addition, management in reclamation land damaged with salinity as well as selecting for cultivars' high tolerance for this stress. Genetic variability, physiological, and agronomical traits related to salinity stress tolerance were estimated by AlKhaishany et al. (2018). Results detected that salinity stress is important and highly impacted all wheat accessions and diminished physio-biochemical indices and agronomic traits, whilst significantly increased free proline and $\mathrm{Na}^{+}$ contents in leaves. Also, agro-morphological traits under investigation may be fruitful and very important to screen, discover, and enhance salinity tolerance in some wheat lines by Yassin et al. (2019) depending on the data of tolerance indices. Shoot length, shoot dry weight, and catalase content traits besides multivariate analysis, clustering, path analysis, and MANOVA were very important indices for genotype characterization to salinity tolerance as well as setting limits for this tolerance (Al-Ashkar et al. (2019)). Saddiq et al. (2019) revealed the methods of decreasing salinity stress in wheat by improving the physiological state of seedlings. The final results detected that using $\mathrm{KCL}, \mathrm{NaCL}$, and $\mathrm{H}_{2} \mathrm{O}$ effectively prevents and relieves the effects of salt stress and ensures good, fast, and equal germination of all seedlings as well as modification of its physiological state in a way that does not affect all future vital processes. The main objective of the present investigation is producing of some wheat genotypes tolerant to salinity stress using mutations within the framework of the process of genetic improvement of wheat to face abiotic stresses with the aim of developing the Egyptian wheat crop.

\section{Materials and methods}

\section{Background of materials under investigation}

This study used Sakha 8 wheat variety, which has excellent morphological and physiological traits that qualify it to be high yielding and distinguished in other agromorphological characters, as well as the physiological traits that make it tolerant to salinity and resistance for many diseases. Therefore, this cultivar is an excellent experimental material that can be used in this study. 


\section{Field evaluation}

The seeds used for the present investigation were originally performed from the wheat research department, Agriculture Research Centre. Two hundred pure seeds of Sakha 8 wheat cultivar with a moisture content of $12 \%$ and highly significant traits such as high yielding and salinity stress tolerance were subjected for gamma irradiation treatment dosages of 200, 300, and $400 \mathrm{~Gy}$ using the Co source at the National Center for Radiation Research and Technology, Nasr City and Cairo, Egypt in 2013 year or M0 generation. The irradiated materials of all doses were grown and series of selections among the mutant population under normal soil conditions in the farm of Sakha city-Kafr Al Sheikh Governorate, and this process carried out four growing seasons from (2013/2014) season or M1 generation to (2016/2017) season or M4 generation, respectively.

\section{Sowing and Treatments}

Two experiments were done during 2017/2018 and $2018 / 2019$ seasons using the original wheat cultivar (Sakha 8) and six M5 mutants derived from it under two treatments as follows:

1) Treatment 1 (normal conditions): The seven wheat genotypes were grown under normal conditions of the soil in the farm of Sakha city in Kafr El-sheikh governorate, Egypt.

2) Treatment 2 (salinity conditions): The seven wheat genotypes were grown under salinity conditions of the soil in the farm of Sirw city in Damietta Governorate, Egypt.

Note: The agriculture was carried out from the second half of November and the harvesting process was done in the first of May in each growing season.

\section{Studied traits}

Fifty plants were taken from each genotype of each treatment for each season (2017/2018 and 2018/2019) to calculate and estimate some agro-morphological and chemical traits related to salinity tolerance as follows:

1) Plant height $(\mathrm{cm})$ : Length of the main culm was measured from the soil surface to the tip of the main panicle at maturity.

2) Number of filled grains/panicle: Filled grains of the main panicle with separated and counted.

3) 1000-grain weight (gm): it was recorded as the weight of 1000 random filled grains per plant.

4) Grain yield/plant (gm): it was recorded as the weight of grain yield of each individual plant, and adjusted to $14 \%$ moisture content.
5) Osmotic pressure (MP): values of the total soluble solids of the cell sap were obtained for the pressed sap of the (fourth upper leaf) tested plants using the Abbe Reflectometer and the osmotic pressure values (in the atmosphere) were calculated by using special tables according to the methods described by Goseve (1960).

6) Proline content: it was quantified by following the method of Bates et al. (1973).

7) Glycine betaine: it was carried out according to the method of Grieve and Grattan (1983).

8) Trehalose contents: it was carried out according to the method of Grieve and Grattan (1983).

\section{Experiment design}

All materials were grown with four replicates of each treatment for each growing season in a randomized complete block design. Fertilizer was added at a recommended rate, and hand weeding was done when needed. During the growth period, all the data for all studied traits were estimated and calculated.

\section{Classification of replicate}

Length of row: $15 \mathrm{~m}$, width of replicate: $6.30 \mathrm{~m}$, space within plants in the same row: $20 \mathrm{~cm}$, space within rows: $30 \mathrm{~cm}$; and each genotype were sowing in three rows.

Experimental replicate area $\left(\mathrm{m}^{2}\right): 15 \times 6.30=94.5 \mathrm{~m}^{2}$

\section{Statistical analysis}

All calculated data of all traits under evaluation in two seasons for both treatments were analyzed using the formula by Gomez and Gomez (1984).

\section{Estimation of salinity tolerance indices}

All salinity tolerance indices were estimated according to Fischer and Maurer (1978), Bouslama and Schapaugh (1984), Lin et al. (1986), Hossain et al. (1990), Fernandez (1992), Gavuzzi et al. (1997), and Golestani and Assad (1998) as follows:

$$
\begin{aligned}
\mathrm{MS} & =\mathrm{YS}+\mathrm{YP} / 2, \mathrm{STI}=\mathrm{YP}+\mathrm{YS} / \text { mean of } \mathrm{YP}^{2}, \mathrm{GMP} \\
& =(\mathrm{YP} \times \mathrm{YS})^{0.5}, \mathrm{YI}=\mathrm{YS} / \text { mean of YS, YSI } \\
& =\mathrm{YS} / \mathrm{YP},(\mathrm{YR})=1-\mathrm{YS} / \mathrm{YP}, \mathrm{SSI}=(1-\mathrm{YS} / \mathrm{YW}) / \mathrm{D} .
\end{aligned}
$$

\section{Genetic parameters}

Variance components, heritability in a broad sense, genetic coefficient of variability (GCV\%), phenotypic coefficient of variability $(\mathrm{PCV} \%), D^{\mathrm{z}}$ or the difference between the phenotypic coefficient of variation (PCV\%) and genotypic coefficient of variation (GCV\%), expected genetic advance in addition, and genetic advance as a percentage of mean were the most important measurements calculated through the 
two seasons for both treatments in this investigation as follows:

The genetic coefficient of variability (GCV\%) and phenotypic coefficient of variability (PCV\%) were estimated according to the method suggested by Burton and Devane (1953) as follows:

Environmental variance $\left(\sigma^{2} \mathrm{e}\right)=\mathrm{MS}_{\mathrm{e}}$

Genotypic variance $(\mathrm{G} v)$ or $\left(\sigma^{2} \mathrm{~g}\right)=\mathrm{MS}_{\mathrm{g}}-\mathrm{MS}_{\mathrm{e}} / r$

Phenotypic variance $(\mathrm{Ph} \mathrm{v})$ or $\left(\sigma^{2} \mathrm{ph}\right)=\left(\sigma^{2} \mathrm{e}\right)+\left(\sigma^{2} \mathrm{~g}\right)$ or $\mathrm{MS}_{\mathrm{e}}+\mathrm{MS}_{\mathrm{g}}$

where MSe is the mean square of error, MSg is the mean square of genotypes, is the $r=$ number of replicates, and $X$ is the mean of trait.

Genetic coefficient of variability $(\mathrm{GCV} \%)=\frac{\sqrt{\mathrm{Gv}}}{\mathrm{X}} \times 100$

Phenotypic coefficient of variability $(\mathrm{PCV} \%)=\frac{\sqrt{\mathrm{Ph} v}}{\mathrm{X}} \times 100$

\section{Estimation of heritability in a broad sense}

Broad sense heritability $\left(h^{2}\right)$ expressed as the percentage of the ratio of the genotypic variance ( $g$ v) to the phenotypic variance ( $\mathrm{ph} v$ ) and was estimated on genotype mean basis as described by Burton and Devane (1953) and Johnson et al. (1955) as:

$$
\mathrm{H}^{2} \mathrm{~B}=\left(\sigma^{2} \mathrm{~g}\right) /\left(\sigma^{2} \mathrm{ph}\right) \times 100
$$

$D^{\mathrm{z}}$ : The difference between the phenotypic coefficient of variation $(\mathrm{PCV} \%)$ and genotypic coefficient of variation $(\mathrm{GCV} \%)$ or $(\mathrm{PCV} \%)-(\mathrm{GCV} \%)$.

\section{Estimation of genetic advance}

The expected genetic advance (GA) and percentage of the mean (GAM) assuming selection of superior $5 \%$ of the genotypes were estimated in accordance with the methods illustrated by Johnson et al. (1955) as follows:

$$
(\mathrm{GA})=K \times\left(\sigma^{2} \mathrm{~g}\right) \times \sqrt{\mathrm{Ph} \mathrm{v}} / \mathrm{Ph} \mathrm{v}
$$

where $K$ is the standardized selection differential at $5 \%$ selection intensity $(K=2.068)$.

The genetic advance as a percentage of the mean (GAM) was computed as follows:

$$
(\mathrm{GAM} \%)=(\mathrm{GA}) / \text { mean } \times 100
$$

\section{Molecular depiction}

Molecular genetics contributed to a positive, large, and an effective role in finding the genetic differences between any genotypes, which may be the taxonomic basis for these new lines and the local wheat cultivar at the molecular level. This has helped in determining the genetic parameters (alleles or genes) responsible for resisting all stresses of various kinds especially salinity tolerance. Molecular markers also have played a functional role in drawing the phylogenetic tree through cluster analysis to indicate the genetic relationship between different accessions besides the extent of environmental and genetic compatibility among them (each of them can compatibility and grow together).

\section{Molecular marker ISSR profiles}

Total DNA extraction: the extraction method was applied according to the manfacturer of Wizard ${ }^{\circ}$ Genomic DNA Purification Kit Promega using Inter Simple Sequence Repeats (ISSR) analysis was applied according to Zietkiewicz et al. (1994) and procured from UBC (the University of British Columbia, Biotechnology Laboratory, Vancouver, Canada) based on core repeats anchored at the 5 or 3 end as shown in Table 6. DNA of seven wheat varieties was amplified using Taq-DNA polymerase chain reaction (PCR) according to the manufacturer's instructions (Promega \# TM048) for ISSR primers. The PCR consisted of a 5-min incubation period at $94{ }^{\circ} \mathrm{C}$ followed by 40 cycles of $94{ }^{\circ} \mathrm{C} / 30 \mathrm{~s}$ (38, 40, 41, and $\left.45^{\circ} \mathrm{C}\right) / 1 \mathrm{~min}$ and $72^{\circ} \mathrm{C} / 2 \mathrm{~min}$, with a final extension step of $72{ }^{\circ} \mathrm{C} / 7 \mathrm{~min}$. The PCR product was separated by $1.5 \%$ agarose gel electrophoresis using a TAE buffer and $0.04 \%$ red safe dye.

Data handling and cluster analysis (phylogenetic tree)

Data was scored for computer analysis on the basis of the presence or absence of the amplified products for each primer. Pairwise components of the seven wheat genotypes based on the presence or absence of unique and shared polymorphic products were used to determine similarity coefficients according to Jaccard (1908). The similarity coefficients according to Jaccard (1908) also were then used to construct dendrograms or cluster analysis, using the unweighted pair group method with arithmetic averages (UPGMA) employing the SAHN (sequential, agglomerative, hierarchical, and nested clustering) from the NTSYS-PC (Numerical Taxonomy and Multivariate Analysis System), version 1.80 (Applied Biostatistics Program).

\section{Results}

Analysis of variance

Data shown in Table 1 related to the chemical analysis among the two treatments besides results obtained in Table 2 associated with the analysis of variance test (ANOVA) detected that significant and highly significant differences between all wheat genotypes (the original cultivar Sakha 8 and its six M5-derived mutants) for all studied traits under normal and saline conditions during the two seasons (2017/2018 and 2018/2019). The coefficient of variance percentage was low for all calculated 
Table 1 Chemical classification of normal and salinity soils

\begin{tabular}{lll}
\hline Characteristics & Normal soil (Sakha city) & Saline soil (Sirw city) \\
\hline EC (dS/m) & 2.34 & $9.68-10.41$ \\
$\mathbf{p H}(\mathbf{1 : 2 . 5 )}$ & 8.20 & 8.57 \\
$\mathbf{T D S} \mathbf{~ m g / l ~ ( p p m ) ~}$ & 377.18 & $5704-5809$ \\
$\mathbf{C a}^{++}$ & 1.98 & 14.58 \\
$\mathbf{M g}^{++}$ & 1.22 & 12.55 \\
$\mathbf{N a}^{+}$ & 9.67 & $51.04-57.34$ \\
$\mathbf{K}^{+}$ & 0.53 & 0.28 \\
$\mathbf{C O}_{\mathbf{3}^{--}}$ & 0.07 & 0.18 \\
$\mathbf{H C O}_{\mathbf{3}^{-}}$ & 1.97 & 1.26 \\
$\mathbf{C l}^{-}$ & 12.55 & 45.66 \\
$\mathbf{S O}_{4^{-}}$ & 1.57 & 15.62 \\
Texture & Clay & Clay \\
\hline
\end{tabular}

$E C$ electrical conductivity, TDS total dissolved salts

*Measure of soil saturation

${ }^{* *}$ Measure of soil water extract 1:5

traits under both conditions for the two seasons except osmotic pressure trait where it was very high under normal and salinity treatments in both seasons, where it was recorded (144.03\% and 152.05\%) for season 2017/ 2018 and (116.93\% and 121.19\%) for season 2018/2019 under normal and salinity conditions, respectively.

\section{Mean performance}

Results obtained in Table 3 showed that the entries (Sakha 8; mutants 3, 5, and 6) for plant height and the number of filled grains/panicle traits (Sakha 8; mutants 2, 3, and 5) for 1000-grain weight trait (Sakha 8; mutant 1,2 , and 5) for grain yield/plant trait (mutants $1,4,5$, and 6) for osmotic pressure trait (mutants 1, 2, 5, and 6) for proline content trait (mutants 2, 3, 4, and 5) for glycine betaine trait (Sakha 8; mutants 1, 2, and 5), and for trehalose content trait were exhibited the highest mean values under normal and salinity conditions in both seasons. For example but not limited to, the mean values were ranged from 108.24 to $123.43 \mathrm{~cm}$ and from 106.14 to $117.80 \mathrm{~cm}$ in season $2017 / 2018$ and ranged from 107.13 to $121.18 \mathrm{~cm}$ and 104.0 to $116.23 \mathrm{~cm}$ in season 2018/2019 for plant height trait under both treatments. For the 1000-grain weight trait, data was ranged from 45.12 to $67.03 \mathrm{~g}$ and from 34.05 to $52.96 \mathrm{~g}$ in season $2017 / 2018$ and ranged from 43.07 to $64.02 \mathrm{~g}$ and from 29.11 to $55.13 \mathrm{~g}$ in season 2018/2019 under normal and salinity treatments. Results were ranged from 42.35 to $75.44 \mathrm{~g}$ and from 29.33 to $63.17 \mathrm{~g}$ in the first season and ranged from 45.0 to $77.26 \mathrm{~g}$ and from 25.71 to 58.22 $\mathrm{g}$ in the second season for grain yield/plant trait under both treatments. With respect to proline content, it was ranged from 48.60 to 80.07 and from 56.01 to 89.65 in season $2017 / 2018$ and ranged from 51.17 to 78.33 and ranged from 73.12 to 95.14 in season 2018/2019 under normal and salinity conditions, respectively.

\section{Salinity tolerance indices}

Results presented in Table 4 showed that the entries (Sakha 8, mutant 2 and 6) for YSI in season 2017/2018 and (Sakha 8; mutants 1 and 2) for the same parameter in season 2018/2019 in addition, the genotypes (Sakha 8; mutants 1, 2, 3, and 5) for MP and (Sakha 8; mutants 1 and 2) for GMP in both years exhibited the highest mean values in this investigation. This fact means that these previous accessions were recorded highly limit of salinity tolerance. On the same regard, the entries (Sakha 8; mutants 1 and 2) for YI in both growing seasons and (Sakha 8 and mutant 2) for STI in season 2017/2018 and (Sakha 8; mutants 1 and 2) for the same parameter in season2018/2019 were detected with mean values higher than the unity. This confirmed that these materials revealed high tolerance under salinity stress compared with the control, respectively. In the opposite direction, all genotypes understudying for YR in the first year and (mutants 3, 4, 5, and 6) for the same parameter in the second season besides the accessions (Sakha 8; mutants 2 and 6) in season 2017/2018 and (Sakha 8; mutants 1 and 2) in season 2018/2019 for SSI were recorded mean values lower than one which indicated that these entries were detected highly tolerance for salinity stress compared with the normal conditions.

\section{Genetic parameters}

Data showed in Table 5 detected that heritability in a broad sense was high in the studied traits; plant height under normal conditions only for the two seasons $(80.93 \%$ and $83.60 \%)$, grain yield/plant under salinity conditions only for both years (63.01\% and 90.33\%), osmotic pressure under stress treatment only for the two seasons (67.22\% and 70.25\%), proline content under normal and salinity conditions and the values were $66.66 \%$ and $68.97 \%$ for the first season and $74.19 \%$ and $86.79 \%$ for the other one, glycine betaine content for the two treatments for both years $(86.23 \%$ and $75.11 \%$, and $68.82 \%$ and $63.87 \%$ ), and trehalose content for the same treatments in both seasons $(76.93 \%$ and $73.18 \%$, and $80.96 \%$ and $93.29 \%$ ), respectively, while values of heritability in a broad sense were ranged from low to medium for the rest calculated traits under the same conditions in both seasons. Results of GCV\% and PCV\% were low under normal and salinity conditions in both years for all traits understudying except osmotic pressure trait where it exhibited the highest values of this parameter under all conditions as $106.06 \%$ and $217.78 \%$ under both treatments for the first season and recorded $102.36 \%$ and $186.24 \%$ under normal and stress conditions in the second season for GCV\% and recorded 


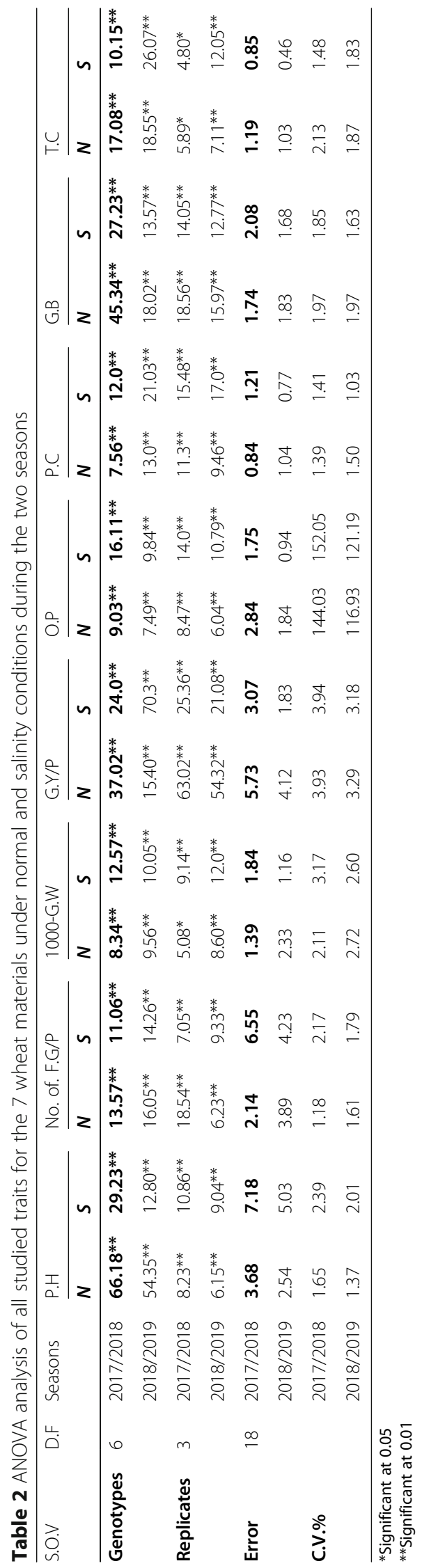




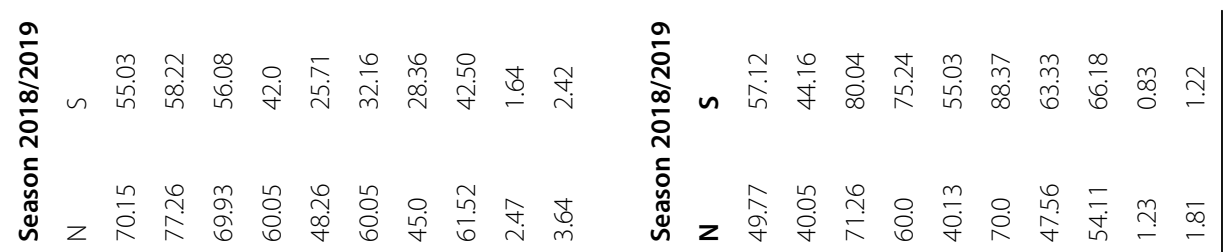

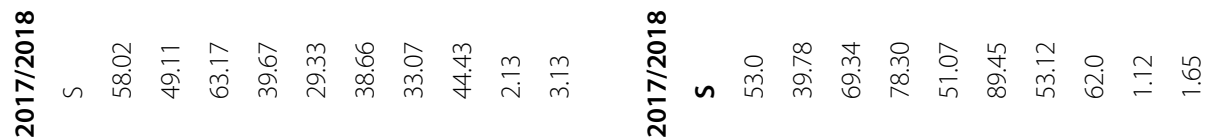

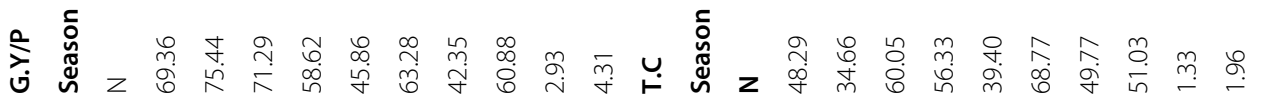

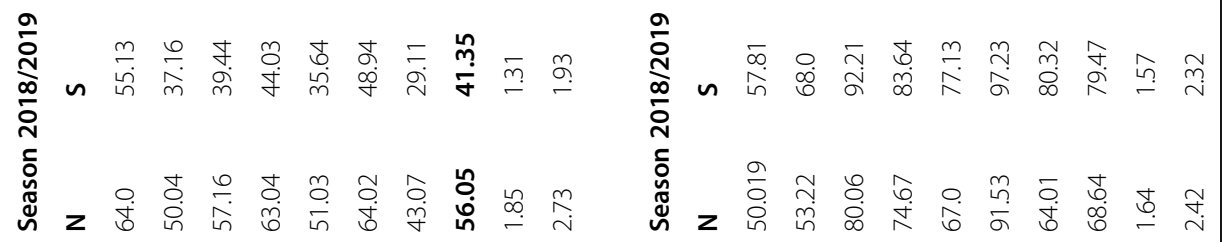

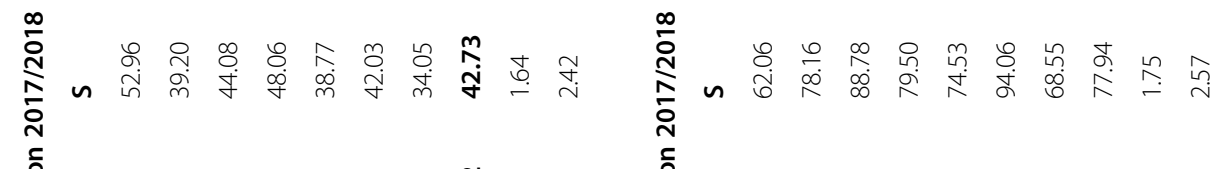

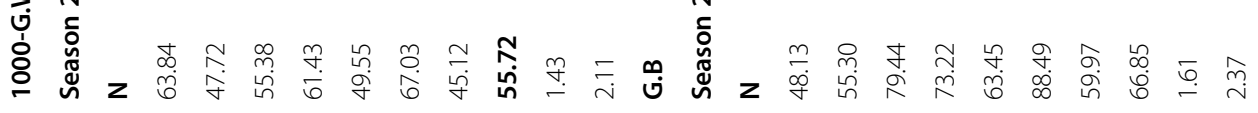

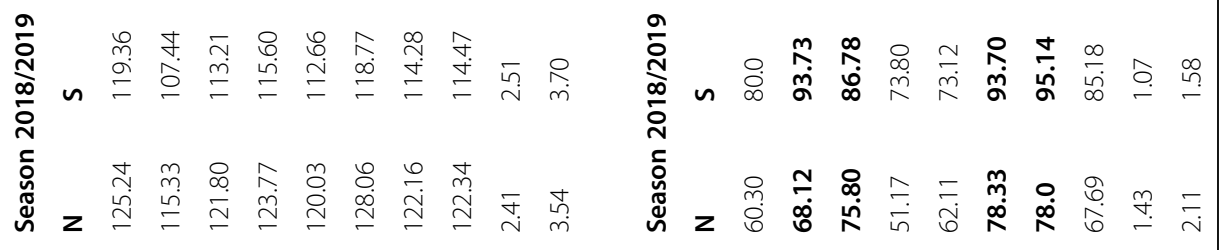

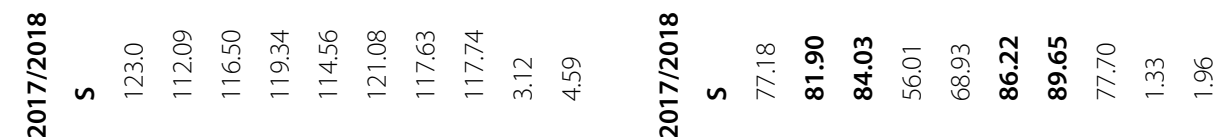

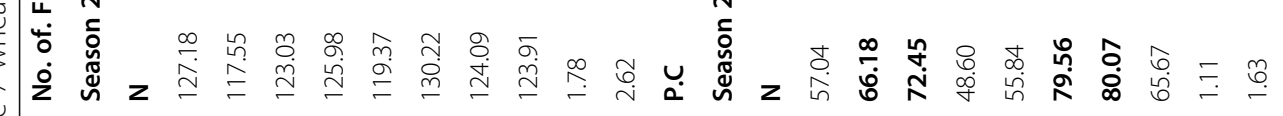

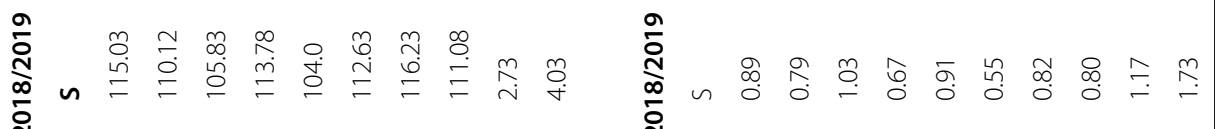

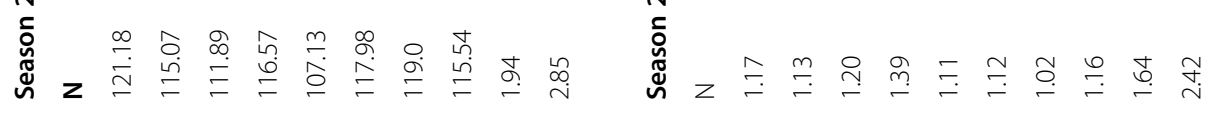

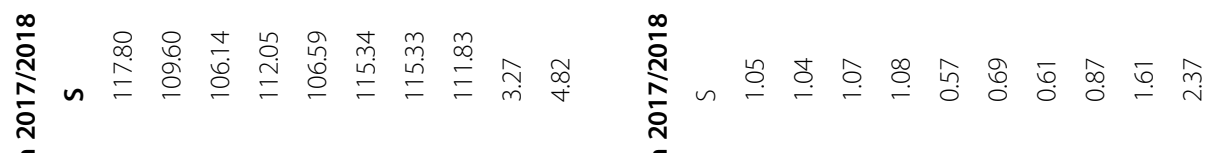

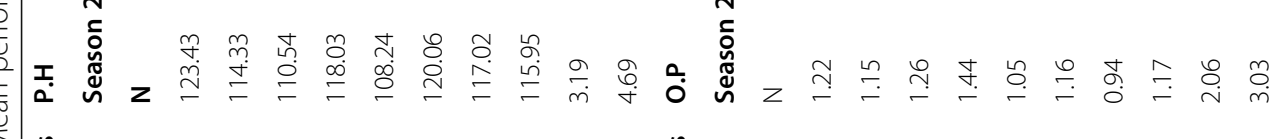

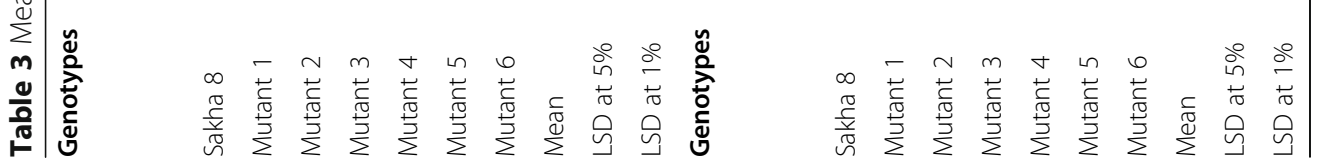




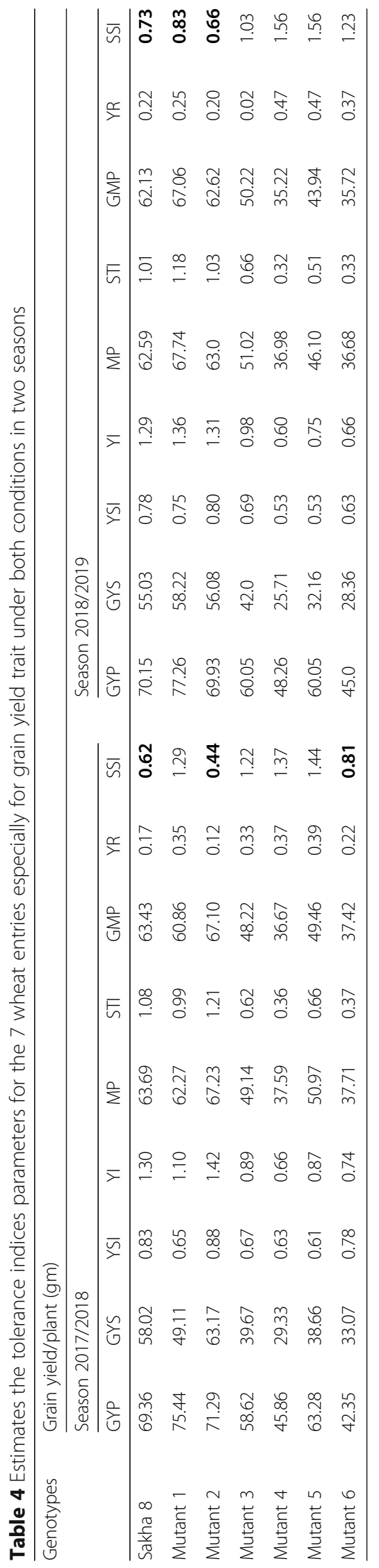




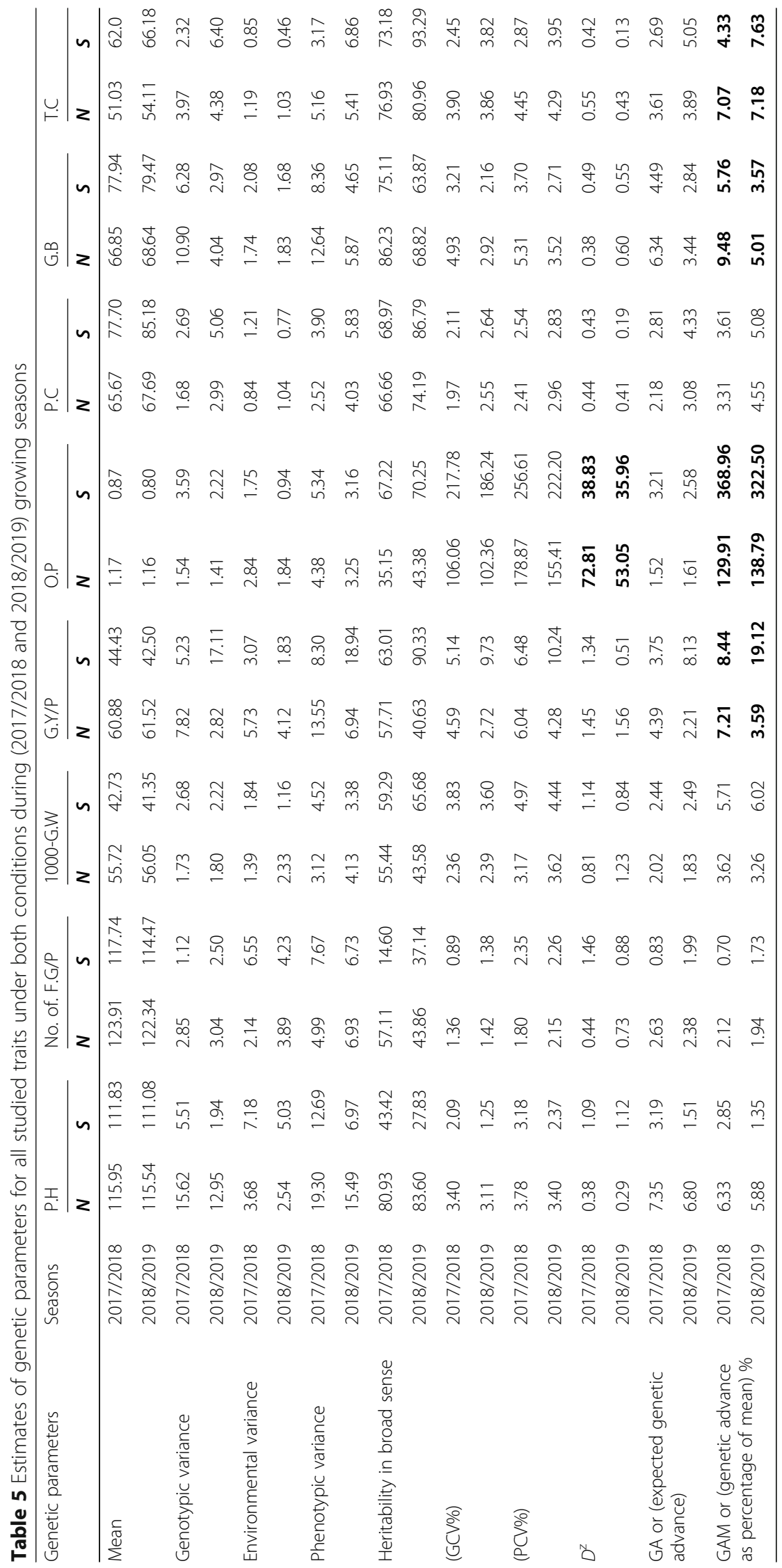


178.87 and 265.61 under both treatments in season 2017/ 2018 and 155.41 and 222.20 for the same treatments in the second year 2018/2019 for PCV\%, respectively. The differences between the phenotypic and genotypic coefficient of variation $\left(D^{\mathrm{Z}}\right)$ were low for all studied traits in both growing seasons under both treatments except osmotic pressure trait where it recorded 72.81 and 38.83 for 2017/2018 season and 53.05 and 35.96 for 2018/2019 season under normal and salinity conditions, respectively. Data assessment of expected genetic advance (GA) based on $5 \%$ selection confirmed that all values evaluated during the two seasons under both treatments were low for all studied traits in this regard. Genetic advance as a percentage of the mean GAM\% was recorded as the highest limit for this parameter especially in osmotic pressure trait where it exhibited 129.91 and 368.96 under both treatments in season 2017/2018 and recorded 138.79 and 322.50 under both treatments for the second season. In addition, some traits showed well results under both treatments during the two seasons such as glycine betaine, trehalose contents, and grain yield/plant, respectively.

\section{Molecular depiction}

Molecular description using ISSR primers

\section{ISSR analysis profile}

The six ISSR primers; 17898-A, 17899-A, 17898-B, 17899-

B, 844-B, and HB-14 produced a total of 173 markers, 12 of them were monomorphic, while that 161 bands appeared polymorphic with 93\% (polymorphism) included 63 unique bands (56 of them were positive markers besides 7 negative markers) as shown in Fig. 1 and Table 6 . The average numbers of polymorphic ISSR markers were 26.83 fragments for each primer. Polymorphic fragments number ranged from 11 to 22 and molecular size ranging from 2540 to $148 \mathrm{bp}$, respectively. The highest number of polymorphic bands (22) were observed in $17899-\mathrm{B}$ primer, followed by $17898-\mathrm{A}$ and 17899-A (20 bands) for each of them and then followed by the two primers $844-\mathrm{B}$ and $17898-\mathrm{B}$ where they recorded (17 and 15) fragments for each of them, respectively. The lowest number of polymorphic bands (11) was showed in HB-14 primer, respectively. The results in Table 6 and Fig. 2 revealed that the highest polymorphism percentage was observed in 17898-A primer (100\%), followed by $844-\mathrm{B}$ primer $(97.29 \%)$, followed by 17899-A primer (92.308\%), followed by 17898 -B primer (91.667\%), followed by HB-14 primer (90.0\%), and then followed by $17899-\mathrm{B}$ primer $(86.486 \%)$, respectively. The highest number of unique bands or positive specific markers (19) appeared in primer 844-B. The highest number of both polymorphic bands (22) and monomorphic band (5) were generated in 17899-B primer. In the same regard, the highest total bands (37) appeared in 17899-B and 844-B primers.

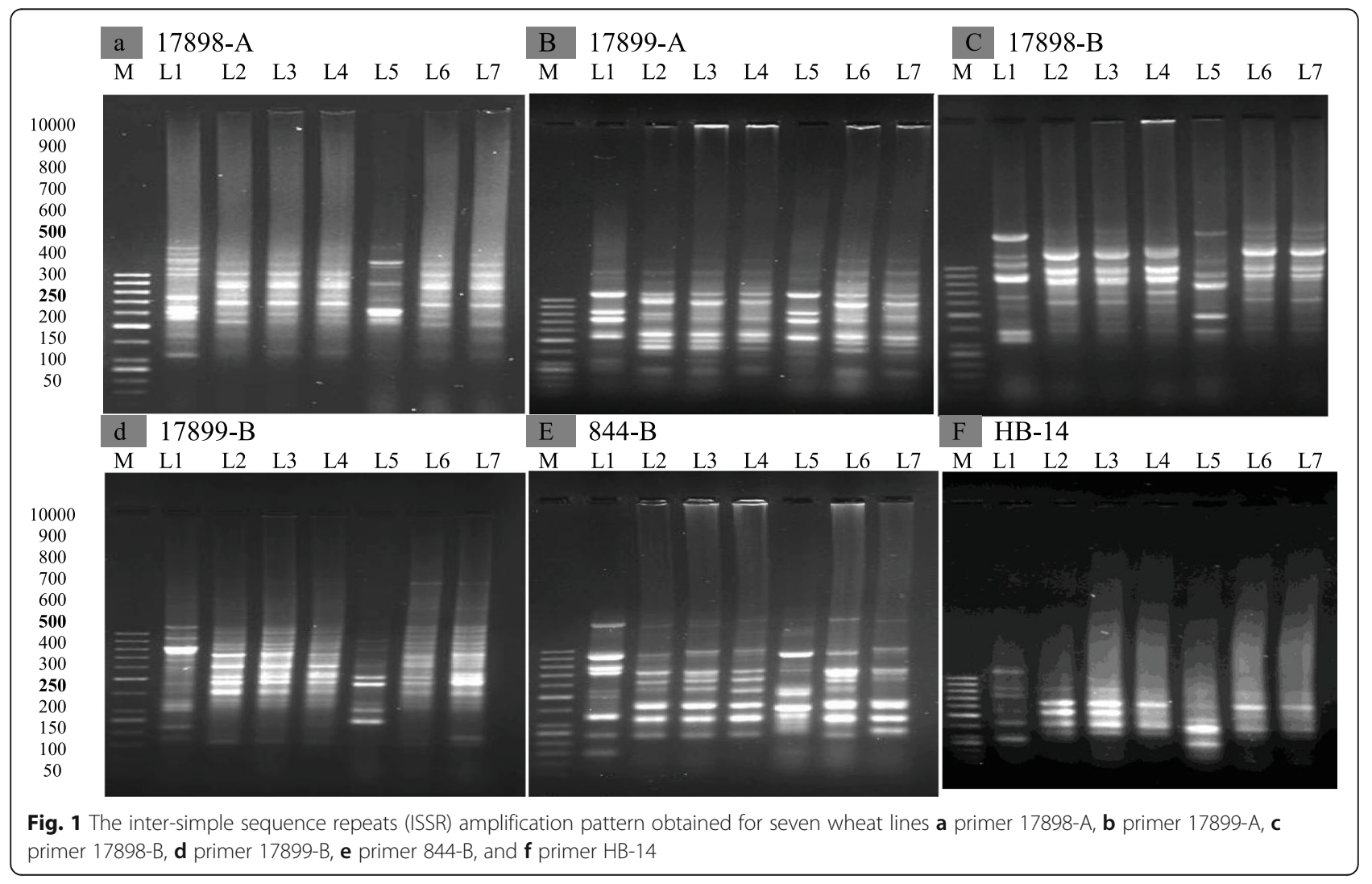


Table 6 Band variation and polymorphism percentage in seven wheat lines using the six ISSR primers

\begin{tabular}{|c|c|c|c|c|c|c|c|c|}
\hline Primers & $\begin{array}{l}\text { Total } \\
\text { bands }\end{array}$ & $\begin{array}{l}\text { Molecular size } \\
\text { (bp) }\end{array}$ & $\begin{array}{l}\text { Number of } \\
\text { monomorphic }\end{array}$ & $\begin{array}{l}\text { Number of unique } \\
\text { band (positive marker) }\end{array}$ & $\begin{array}{l}\text { Number of } \\
\text { polymorphic }\end{array}$ & Polymorphism \% & Sequence & Annealing \\
\hline 17898-A & 29 & $1525-214$ & 0 & 9 & 20 & $100 \%$ & $5^{\prime}-(C A) 6 A C-3^{\prime}$ & $38^{\circ} \mathrm{C}$ \\
\hline 17899-A & 26 & $2540-176$ & 2 & 4 & 20 & $92.308 \%$ & $5^{\prime}-(C A) 6$ AG-3' & $38^{\circ} \mathrm{C}$ \\
\hline 17898-B & 24 & 2173-148 & 2 & 7 & 15 & $91.667 \%$ & 5'-(CA)6 GT-3' & $40^{\circ} \mathrm{C}$ \\
\hline 17899-B & 37 & $2381-161$ & 5 & 10 & 22 & $86.486 \%$ & $5^{\prime}-(C A) 6$ GG-3' & $41^{\circ} \mathrm{C}$ \\
\hline 844-B & 37 & 1915-164 & 1 & 19 & 17 & $97.297 \%$ & $5^{\prime}-(\mathrm{CT}) 8 \mathrm{GC}-3^{\prime}$ & $45^{\circ} \mathrm{C}$ \\
\hline HB-14 & 20 & $1262-190$ & 2 & 7 & 11 & $90 \%$ & $5^{\prime}-(\mathrm{CTC}) 3 \mathrm{GC}-3^{\prime}$ & $38^{\circ} \mathrm{C}$ \\
\hline Total & 173 & $2540-148$ & 12 & 56 & 105 & $93 \%$ & & \\
\hline
\end{tabular}

In the same context, 17899-A primer exhibited the lowest number of unique bands or positive specific markers (4) while the lowest polymorphism percentage (86.486\%) appeared in 17899 -B primer.

Results obtained in Table 7 revealed that line 1 and line 3 recorded the highest number of amplified fragments (73 and 76) for each of them, while line 5 showed the lowest number of bands (56) and the rest lines were exhibited different numbers of amplified fragments. In the same regard, it is noted that primers $17899-\mathrm{B}$ and 17899-A recorded the highest number of bands (115 and 90) together of all studied genotypes. But HB-14 primer gave the lowest number of amplified fragments (55) for the same materials.

Data viewed in Table 8 detected 63 markers (56 of them were positive and 7 negative specific markers) generated from 6 ISSR primers using to identify among 7 wheat accessions. Results showed that 17898-A primer exhibited 10 specific markers ( 9 positive and one negative) as follows: six positive markers were generated in line 1 with sizes $1290.09,1127.28,636.04,544.53$, 380.01 , and $314.87 \mathrm{bp}$; two positive markers for line 5 with sizes 1150.56 and $707.37 \mathrm{bp}$; one positive marker for line 7 with size $404.04 \mathrm{bp}$; and one negative marker only for line 5 with size $752.10 \mathrm{bp}$, respectively. For
17899-A primer, four positive markers were observed in this regard where two positive markers with sizes 1586.04 and $512.02 \mathrm{bp}$ for line 1 and the other two positive markers with sizes 703.7 and 222.75 bp were generated in line 7 , respectively, while 17898 -B primer was showed 10 specific markers where (7 of them were positive and 3 negative) as follows: four positive marker for line 1 with molecular sizes 1194.57, 930.92, 637.24, and $281.24 \mathrm{bp}$, one positive marker with size $499.08 \mathrm{bp}$ for line 4 , one positive marker with size 785.73 bp for line 5 , and one positive marker with size $421.24 \mathrm{bp}$ for line 6 . The three negative markers were observed in lines 1 and 5 with sizes 1059.81 and 944.96 bp for line 1 and 1373.6 bp for line 5, respectively. In the same context, 17899-B primer recorded 11 specific markers (10 positive and one negative). Three positive markers were generated in line one with sizes (1053.44, 1040.88, and $220.6 \mathrm{bp}$ ), one positive marker with size 2353.19 bp for line 4 , two positive markers with sizes 326.43 and 246.74 bp for line 5 , four positive markers with sizes $(689.5,544.6,492.79$, and $381.52 \mathrm{bp}$ ) for line 7 , and one negative marker only was observed in line 5 with size $393.93 \mathrm{bp}$, respectively. 844-B primer exhibited 20 markers where 19 of them were positive besides one negative marker only. Positive markers were as follows: six positive markers for line

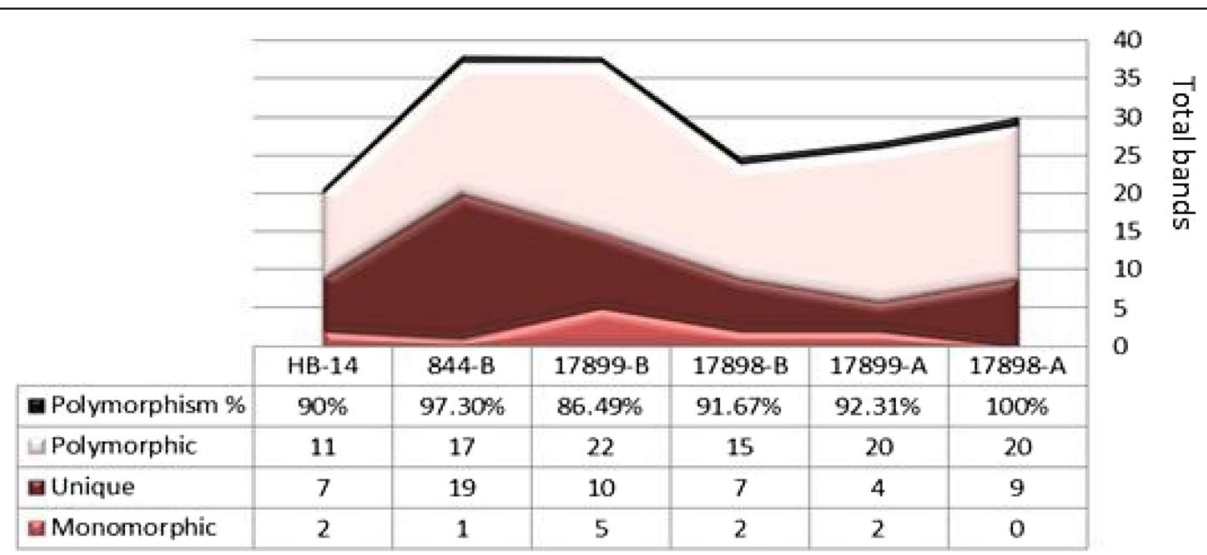

Fig. 2 The relationship between total bands and monomorphic, unique, polymorphic, and polymorphism percentage of six ISSR primers used for the detection of seven wheat lines 
Table 7 Total bands produced from each primer for 7 wheat lines and all amplified fragments in each genotype

\begin{tabular}{|c|c|c|c|c|c|c|c|}
\hline \multirow[t]{2}{*}{ Genotypes } & \multicolumn{7}{|l|}{ Primers } \\
\hline & 17898-A & 17899-A & 17898-B & 17899-B & $844-B$ & HB-14 & Total \\
\hline Line 1 & 14 & 11 & 12 & 17 & 11 & 8 & 73 \\
\hline Line 2 & 9 & 14 & 12 & 15 & 11 & 8 & 69 \\
\hline Line 3 & 9 & 16 & 13 & 15 & 13 & 10 & 76 \\
\hline Line 4 & 9 & 13 & 11 & 16 & 12 & 7 & 68 \\
\hline Line 5 & 9 & 9 & 8 & 11 & 11 & 8 & 56 \\
\hline Line 6 & 10 & 13 & 12 & 18 & 11 & 6 & 70 \\
\hline Line 7 & 9 & 14 & 12 & 23 & 8 & 8 & 74 \\
\hline Total Bands & 69 & 90 & 80 & 115 & 77 & 55 & 486 \\
\hline
\end{tabular}

one with sizes $(813.27,513.51,478.95,423.98,376.63$, and $164.39 \mathrm{bp})$, two positive markers for line 2 with sizes 1434.87 and $796.45 \mathrm{bp}$, one positive marker for line 3 with size $692.86 \mathrm{bp}$, two positive markers for line 4 with sizes 1863.24 and $653.02 \mathrm{bp}$, five positive markers for line 5 with sizes $1570.89,827.56,492.49,296.16$, and $265.85 \mathrm{bp}$, one positive marker for line 6 with size $700.14 \mathrm{bp}$, and two positive markers were observed in line 7 with molecular sizes of 779.97 and $252.32 \mathrm{bp}$, respectively. While the only negative marker was shown in line 1 with size $403.80 \mathrm{bp}$. Eight specific markers were generated by HB-14 primer where 7 of them were positive and one only negative. The seven positive markers were observed in line 1 with sizes 1262.81 and 271.49 $\mathrm{bp}$, one positive marker with size $1017.16 \mathrm{bp}$ for line 3, two positive markers with sizes 411.06 and 236.62 bp for line 5 , and two positive markers were showed in line 7 with sizes 659.92 and $427.06 \mathrm{bp}$, respectively. While one negative marker was observed in line 1 only with size 311.48 bp.

\section{Proximity matrix analysis (genetic similarity)}

Data viewed in Table 9 exhibited 21 pairwise comparisons to debate the genetic relationships among 7 wheat accessions detected in terms of similarity. The genetic similarity ranged from 0.191 to 0.746 with an average of 0.468 , where the biggest value of genetic similarity was 0.746 between L2 and L3 and the lowest value of similarity was 0.191 among L1 and L6, respectively. Also, highly genetic similarity values were observed for example within L3 and L4, L2 and L4, and L6 and L7 and their values were $0.714,0.650$, and 0.636 , respectively. The rest data of genetic similarity exhibited values appeared low.

\section{Cluster analysis (phylogenetic tree)}

Results obtained from cluster analysis and presented in Fig. 3 divided all wheat lines into two main clusters. The cluster I included L5 while cluster II contained two subclusters. The subcluster 1 included L6 and L7 while subcluster 2 divided into L1 only and one sub-sub cluster. The sub-sub cluster included one group (L2 and L3) besides (L4), respectively.

\section{Discussion}

Results obtained in Table 2 confirmed that the seven wheat materials (Sakha 8 and its six M5-derived mutants) were different genetically from each other especially the six wheat mutants which descended from one species. These new materials were all genetically different from each other and from the original variety that descended from it. On the other counterpart, cultivating these genotypes over two growing seasons (2017/2018 and 2018/2019) also proved highly genetic stability and the differences within the seasons that emerged were only environmental. This fact confirms two things that the first one is succeeding in mutagenic events by different levels of gamma rays which would make positive changes in all agro-morphological traits in the original variety (Sakha 8) especially high yielding. The second result is reaching to a high limit of genetic stability for the six wheat mutants by $100 \%$ after five segregation generations. These results were in agreement with those reported by El-Keredy et al. (2003), ElMouhamady et al. (2010), El-Mouhamady et al. (2011), ElSeidy et al. (2013), El-Mouhamady et al. (2016), Khatab et al. (2017), Al-Khaishany et al. (2018), El-Mouhamady et al. (2019), and Yassin et al. (2019).

Using different levels of gamma rays to irradiate the Egyptian wheat variety (Sakha 8) has proved more remarkable and also flawed results in the discovery of six excellent mutations descended from this variety and characterized it by reaching to the highest limit of genetic stability after cultivating it for five segregation generations (Table 3). These new genotypes gave great tolerance for salinity stress over two growing seasons (2017/2018 and 2018/2019) compared to the original parent that descended from it and were exhibited very promising results for all traits understudying for the salinity treatment compared to the control. This tolerance 
Table 8 Mapping of positive $(P)$ and negative specific markers for the 7 wheat lines using six ISSR primers

\begin{tabular}{|c|c|c|c|c|c|c|c|c|c|}
\hline ISSR primers & MS (bp) & L1 & L2 & L3 & $\llcorner 4$ & L5 & L6 & L7 & $(\mathrm{P}$ or $\mathrm{N})$ marker \\
\hline \multirow[t]{10}{*}{ 17898-A } & 1290.09 & + & - & - & - & - & - & - & $\mathrm{P}(\mathrm{L} 1)$ \\
\hline & 1150.56 & - & - & - & - & + & - & - & $P(L 5)$ \\
\hline & 1127.28 & + & - & - & - & - & - & - & $P(L 1)$ \\
\hline & 752.10 & + & + & + & + & - & + & + & $N(L 5)$ \\
\hline & 707.37 & - & - & - & - & + & - & - & $P(L 5)$ \\
\hline & 636.04 & + & - & - & - & - & - & - & $P(L 1)$ \\
\hline & 544.53 & + & - & - & - & - & - & - & $P(L 1)$ \\
\hline & 404.04 & - & - & - & - & - & - & + & $P(L 7)$ \\
\hline & 380.01 & + & - & - & - & - & - & - & $P(L 1)$ \\
\hline & 314.87 & + & - & - & - & - & - & - & $\mathrm{P}(\mathrm{L} 1)$ \\
\hline \multirow[t]{4}{*}{ 17899-A } & 1586.04 & + & - & - & - & - & - & - & $P(L 1)$ \\
\hline & 703.7 & - & - & - & - & - & - & + & $\mathrm{P}(\mathrm{L} 7)$ \\
\hline & 512.02 & + & - & - & - & - & - & - & $P(L 1)$ \\
\hline & 222.75 & - & - & - & - & - & - & + & $P(L 7)$ \\
\hline \multirow[t]{10}{*}{ 17898-B } & 1373.6 & + & + & + & + & - & + & + & $N(L 5)$ \\
\hline & 1194.57 & + & - & - & - & - & - & - & $P(L 1)$ \\
\hline & 1059.81 & - & + & + & + & + & + & + & $N(L 1)$ \\
\hline & 944.96 & - & + & + & + & + & + & + & $N(L 1)$ \\
\hline & 930.92 & + & - & - & - & - & - & - & $P(L 1)$ \\
\hline & 785.73 & - & - & - & - & + & - & - & $P(L 5)$ \\
\hline & 637.24 & + & - & - & - & - & - & - & $P(L 1)$ \\
\hline & 499.08 & - & - & - & + & - & - & - & $P(L 4)$ \\
\hline & 421.24 & - & - & - & - & - & + & - & $P(L 6)$ \\
\hline & 281.24 & + & - & - & - & - & - & - & $P(L 1)$ \\
\hline \multirow[t]{11}{*}{ 17899-B } & 2353.19 & - & - & - & + & - & - & - & $P(L 4)$ \\
\hline & 1053.44 & + & - & - & - & - & - & - & $P(L 1)$ \\
\hline & 1040.88 & + & - & - & - & - & - & - & $P(L 1)$ \\
\hline & 689.50 & - & - & - & - & - & - & + & $\mathrm{P}(\mathrm{L} 7)$ \\
\hline & 544.60 & - & - & - & - & - & - & + & $P(L 7)$ \\
\hline & 492.79 & - & - & - & - & - & - & + & $\mathrm{P}(\mathrm{L} 7)$ \\
\hline & 393.93 & + & + & + & + & - & + & + & $N(L 5)$ \\
\hline & 381.52 & - & - & - & - & - & - & + & $\mathrm{P}(\mathrm{L7})$ \\
\hline & 326.43 & - & - & - & - & + & - & - & $P(L 5)$ \\
\hline & 246.74 & - & - & - & - & + & - & - & $P(L 5)$ \\
\hline & 220.60 & + & - & - & - & - & - & - & $P(L 1)$ \\
\hline \multirow[t]{9}{*}{ 844-B } & 1863.24 & - & - & - & + & - & - & - & $P(L 4)$ \\
\hline & 1570.89 & - & - & - & - & + & - & - & $P(L 5)$ \\
\hline & 1434.87 & - & + & - & - & - & - & - & $P(L 2)$ \\
\hline & 827.56 & - & - & - & - & + & - & - & $P(L 5)$ \\
\hline & 813.27 & + & - & - & - & - & - & - & $P(L 1)$ \\
\hline & 796.45 & - & + & - & - & - & - & - & $P(L 2)$ \\
\hline & 779.97 & - & - & - & - & - & - & + & $P(L 7)$ \\
\hline & 700.14 & - & - & - & - & - & + & - & $P(L 6)$ \\
\hline & 692.86 & - & - & + & - & - & - & - & $P(L 3)$ \\
\hline
\end{tabular}


Table 8 Mapping of positive (P) and negative specific markers for the 7 wheat lines using six ISSR primers (Continued)

\begin{tabular}{|c|c|c|c|c|c|c|c|c|c|}
\hline ISSR primers & MS (bp) & L1 & L2 & L3 & L4 & L5 & L6 & L7 & $(\mathrm{P}$ or $\mathrm{N})$ marker \\
\hline & 653.02 & - & - & - & + & - & - & - & $\mathrm{P}(\mathrm{L} 4)$ \\
\hline & 513.51 & + & - & - & - & - & - & - & $P(L 1)$ \\
\hline & 492.49 & - & - & - & - & + & - & - & $P(L 5)$ \\
\hline & 478.95 & + & - & - & - & - & - & - & $P(L 1)$ \\
\hline & 423.98 & + & - & - & - & - & - & - & $P(L 1)$ \\
\hline & 403.80 & - & + & + & + & + & + & + & $N(L 1)$ \\
\hline & 376.63 & + & - & - & - & - & - & - & $\mathrm{P}(\mathrm{L} 1)$ \\
\hline & 296.16 & - & - & - & - & + & - & - & $P(L 5)$ \\
\hline & 265.85 & - & - & - & - & + & - & - & $P(L 5)$ \\
\hline & 252.32 & - & - & - & - & - & - & + & $\mathrm{P}(\mathrm{L} 7)$ \\
\hline & 164.39 & + & - & - & - & - & - & - & $\mathrm{P}(\mathrm{L} 1)$ \\
\hline \multirow[t]{8}{*}{ HB-14 } & 1262.81 & + & - & - & - & - & - & - & $\mathrm{P}(\mathrm{L} 1)$ \\
\hline & 1017.16 & - & - & + & - & - & - & - & $P(L 3)$ \\
\hline & 659.92 & - & - & - & - & - & - & + & $\mathrm{P}(\mathrm{L} 7)$ \\
\hline & 427.06 & - & - & - & - & - & - & + & $\mathrm{P}(\mathrm{L7})$ \\
\hline & 411.06 & - & - & - & - & + & - & - & $P(L 5)$ \\
\hline & 311.48 & - & + & + & + & + & + & + & $N(L 1)$ \\
\hline & 271.49 & + & - & - & - & - & - & - & $P(L 1)$ \\
\hline & 236.62 & - & - & - & - & + & - & - & $P(L 5)$ \\
\hline Range & 164.39-2353.19 & & & & & & & & \\
\hline Total & & 26 & 9 & 9 & 11 & 16 & 9 & 18 & $63=56(P)+7(N)$ \\
\hline
\end{tabular}

$P$ positive, $N$ negative, MS molecular size

is due to many physiological reasons, including the ability of new genetic genotypes to control the osmotic pressure to reach the lowest levels to maintain the water content within the cell necessary for all vital processes of growth and life under salinity stress. Thus, secreting and composition some chemical compounds that give the characteristic of tolerance and resistance to salinity stress. Controlling the sodium element and reducing its proportion as well besides increasing the level of potassium and all through a precise mechanism have been controlled by the root system. Ultimately, all these reasons are reflected to reduce the rate of loss in yield and

Table 9 Genetic similarity percentages for the seven wheat genotypes using 6 ISSR primers

\begin{tabular}{llllllll}
\hline 0 & $L 1$ & $L 2$ & $L 3$ & $L 4$ & $L 5$ & $L 6$ & $L 7$ \\
\hline$L 1$ & 1.0 & & & & & & \\
$L 2$ & 0.405 & 1.0 & & & & & \\
$L 3$ & 0.354 & $\mathbf{0 . 7 4 6}$ & 1.0 & & & & \\
$L 4$ & 0.305 & $\mathbf{0 . 6 5 0}$ & $\mathbf{0 . 7 1 4}$ & 1.0 & & & \\
$L 5$ & 0.172 & 0.237 & 0.294 & 0.291 & 1.0 & & \\
L6 & $\mathbf{0 . 1 9 1}$ & 0.299 & 0.315 & 0.314 & 0.326 & 1.0 & \\
$L 7$ & 0.204 & 0.276 & 0.282 & 0.267 & 0.203 & $\mathbf{0 . 6 3 6}$ & 1.0 \\
\hline
\end{tabular}

its components under salinity stress compared to the normal conditions (El-Mouhamady (2003); El-Mouhamady (2009); El-Seidy et al. (2013); El-Mouhamady et al. (2014a); El-Mouhamady et al. (2014b); El-Mouhamady et al. (2014c); El-Mouhamady et al. (2014d); Al-Naggar et al. (2015); Heiba et al. (2016a); Khatab et al. (2017); Gadallah et al. (2017); Darwish et al. (2017); Al-Khaishany et al. (2018); Khatab et al. (2019); El-Mouhamady et al. (2019); Tawfik and El-Mouhamady (2019); Yassin et al. (2019); and Al-Ashkar et al. (2019))

The seven superior wheat genotypes including the original cultivar and its six M5-derived mutants have succeeded in demonstrating their high efficiency of salinity tolerance. In addition, minimizing the adverse effect on their different stages of life especially germination, seedling, and other physiological aspects of flowering containing grain fullness and final yield under salinity treatment conditions compared to standard experiment. It is evident by estimating the different parameters of salinity tolerance indices for grain yield per plant in both growing seasons (2017/2018 and 2018/2019) (Table 4). This superiority is due to the high ability of these accessions to reduce the amount of loss in the final yield under salinity stress to a level that plant can accept it and continue in living well without affecting its life or the expected final 


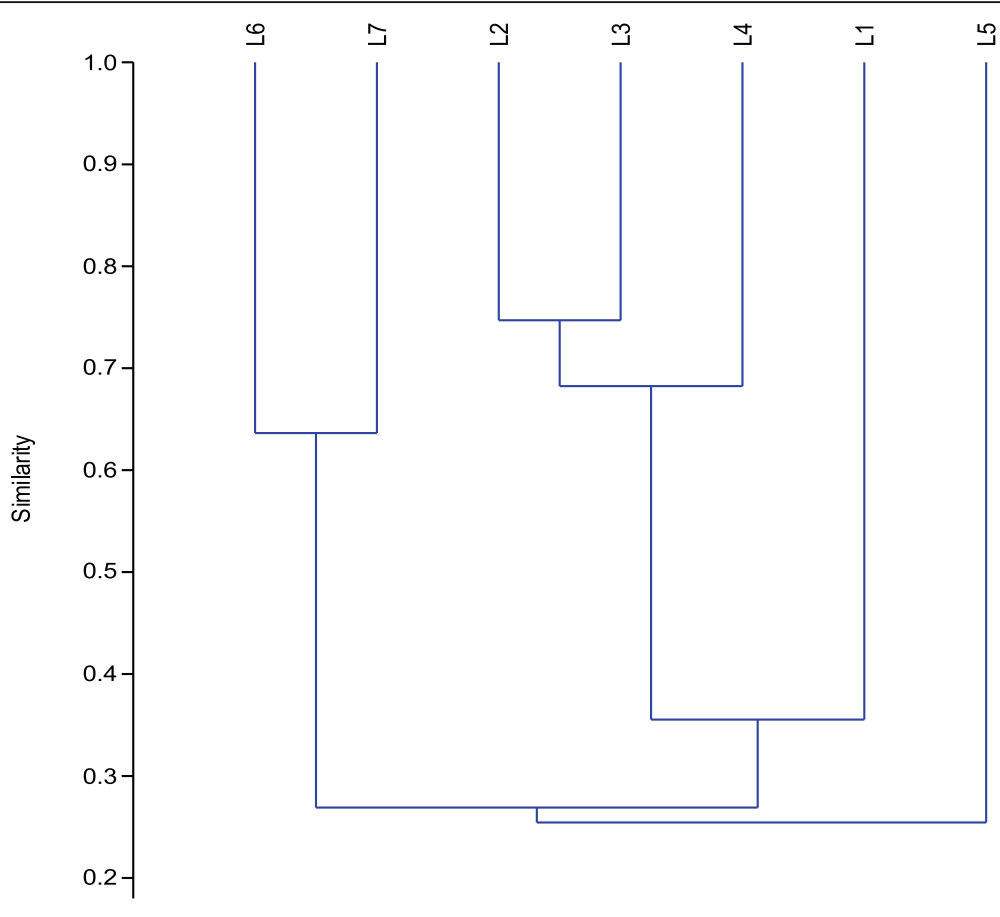

UPGMA

\section{Nei-Li's similarity coefficient}

Fig. 3 Dendrogram representing the genetic relationship among the seven wheat genotypes using UPGMA cluster analysis of Nei-Li's similarity coefficient generated from the six ISSR markers

output and it is very close to natural conditions. One of the mechanisms used by the previous tolerant genetic materials to reduce the bad effect of salinity stress is reducing osmotic pressure to maintain the amount of water needed for all vital processes and also keeping the internal water in the cell from going out during high salinity and prevent the plant to reach the stage of the bollard. In addition, the high limit of the proportion of organic acids and compatible solutes would reduce this bad effect of salinity stress such as proline, trehalose, and glycine betaine contents under salinity conditions compared to the control. All these factors would have formed a degree of tolerance and resistance to salinity stress in this context of this study. These results are in agreement with those reported by Esmail et al. (2016), El-Mouhamady et al. (2016), Ramadan et al. (2016), Darwish et al. (2017), Khatab et al. (2017), ElMouhamady and Habouh (2019), El-Mouhamady et al. (2019), Khatab et al. (2019), Tawfik and El-Mouhamady (2019), and Yassin et al. (2019).

Heritability in a broad sense was viewed high in all studied traits in both seasons under normal and salinity treatments except the number of filled grains/panicle and 1000-grain weight traits where they appeared medium for the 2 years under both treatments (Table 5). This means that low-environment effect in the first case of increasing heritability for these traits besides the genetic variation was the greatest part of phenotypic variation. At the same time, the fruitful and affective role of additive gene action was strongly visible for inheriting and improving these traits for salinity tolerance in the recent wheat accessions through a simple selection process, while that in the second case of medium limit of heritability in a broad sense for the number of filled grains/panicle and 1000-grain weight trait during two seasons under both treatments showed the medium effect for each environment and genetic variation. It confirms that these traits might be governed by nonadditive gene action besides the important role of the interaction among the environment and genotype. This of course will be reflected in the genetic stimulation of increased salt tolerance in wheat lines. PCV\% was always higher than GCV\% in all studied traits for the two seasons under both treatments. This result confirming that all changes in all materials understudying were not only due to genetic variation but also depend on the significant effect of environmental factors and the selection process for these traits under salinity conditions besides the control treatment. Values of genetic advance (GA) in most traits in both years under normal and salinity conditions appeared low might be controlled by non- 
additive gene action. The interaction among genotype and environment on the expression of these traits confirmed the weak affective of individual plant selection for enhancing and increasing salinity tolerance in these traits in the recent genotypes (the Egyptian cultivar and the six mutants) under salinity stress compared to the normal conditions. This does not mean of course that the decline in these values does not only represent a genetic advance, but also attributed to the genetic progress with a significant form in discovering and development of these excellent mutations to tolerate salinity stress in wheat crops. Moreover, the continuation of sowing these new accessions with careful follow-up during the evaluation of yield and its component and tolerance index parameters may eventually lead to raising the mechanism of tolerance and resistance for salinity stress in these lines with maintaining a good proportion of yield. With respect to GAM or (genetic advance as a percentage of mean\%), high results were observed in osmotic pressure trait only under both treatments in both seasons could be indicated the effective role of additive gene action for increasing salinity tolerance. On the other hand, little values observed in the rest traits under both conditions for the two seasons may be due to non-additive gene action for controlling increasing and enhancing salinity stress in these traits. These results were in agreement with those reported by Hamawaki et al. (2012), Abou El-Nasr et al. (2013), Al-Naggar et al. (2015), Shoaib et al. (2016), Chandrawat et al. (2017), ElMouhamady et al. (2017), El-Demardash et al. (2017), Tawfik and El-Mouhamady (2019), El-Mouhamady and Habouh (2019), El-Mouhamady et al. (2019), Al-Kordy et al. (2019), Khatab et al. (2019), Yassin et al. (2019), and AlAshkar et al. (2019).

Molecular genetics and especially molecular markers using 6 ISSR primers have succeeded in drawing a clear, highly accurate picture that includes all the genetic differences at the molecular level for the six salinitytolerant wheat mutants. A clear genetic distinction was made between these new lines compared to the local wheat variety (Sakha 8) through generating a total of 173 amplified fragments by the previous ISSR primers (Table 6 and Fig. 1). Thus, this careful analysis of the molecular markers (ISSR profile analysis) turns out that the primers 17899-B, 17899-A, and 17898-B showed great success in discovering and achieving the largest number of fragments $(115,90$, and 80$)$ that were credited with confirming these molecular genetic differences. This result confirms that the six salinity-tolerant wheat lines were very different among them especially lines 1 and 3 (Fig. 2 and Table 7. These results were in agreement with those obtained by Abdel Sattar and El-Mouhamady (2012), El-Mouhamady et al. (2012a), El-Mouhamady et al. (2012b), El-Mouhamady et al. (2012c), Zian et al.
(2013), Eldessouky et al. (2016), El-Mouhamady et al. (2016), El-Mouhamady et al. (2017), Khatab et al. (2017), Al-Kordy et al. (2019), Khatab et al. (2019), ElMouhamady et al. (2019), Tawfik and El-Mouhamady (2019), and El-Mouhamady and El-Metwally (2020).

Results shown in Table 8 has already succeeded in producing 63 specific markers. These markers consisted 56 positive and 7 negative markers which were considered as a taxonomic and determinant tool for the seven wheat genotypes. Thus, it also have confirmed the saying fact that they differ from each other, an excellent indication and a new dimension to the success for the genetic improvement to salinity tolerance in wheat accessions using mutations. These results were in agreement with those reported by Eldessouky et al. (2016), Al-Kordy et al. (2019), Khatab et al. (2019), El-Mouhamady et al. (2019), Tawfik and El-Mouhamady (2019), and El-Mouhamady and El-Metwally (2020).

There is no doubt that the success achieved from determining the molecular genetic differences between the six salinity-tolerant wheat mutants compared to the local variety (Sakha 8) was the main light to determine the next most important step in this investigation. In a nutshell, this step determines the degrees of genetic similarity and (cluster analysis) or phylogenetic tree (genetic convergence or genetic affinity) among these new genotypes. This strategy will have the greatest impact on determining which of them is genetically and phenotypically compatible with the other. Thus, the purpose of reusing it in the breeding and genetic improvement program for wheat tolerance of biotic and abiotic stresses after these lines reach to a high genetic stability (Table 9 and Fig. 3). These results confirmed that the relationships L2 and L3, L3 and L4, L2 and L4, and L6 and L7 were the most compatible together and gave the highest values of genetic similarity. These results were in agreement with those obtained by Al-Kordy et al. (2019), Khatab et al. (2019), El-Mouhamady et al. (2019), Tawfik and ElMouhamady (2019), and El-Mouhamady and El-Metwally (2020).

\section{Conclusion}

This study succeeded in dealing with the problem of salinity tolerance decreasing in wheat crops with great and radical forms through the optimum use of gamma rays with various doses for improving this purpose in Sakha 8 cultivar wheat. This variety is well known for its tolerance to salinity in a significant way, and this is what made it to be at the forefront of the genetic sources to be used in the study for the improvement and development of salinity tolerance in wheat crops not only locally, but internationally. Also, this investigation devised six M5 mutants derived from the original cultivar (Sakha 8) which have been confirmed with high genetic stability through its cultivation over 2 years under 
normal and salinity conditions. All results of mean values and genetic parameters for all studied traits in Sakha 8 wheat cultivar and its six M5-derived mutants under both treatments in the two seasons (2017/2018 and 2018/2019) were proved highly significant and were very distinctive for salinity tolerance. Molecular characterization as well using six ISSR primers confirmed that the six wheat mutants were significantly different from each other and from the original cultivar descending from it through generating 63 specific markers.

\begin{abstract}
Abbreviations
1000-G.W: 1000-grain weight; $D^{z}$ : The difference between the phenotypic coefficient of variation (PCV \%) and genotypic coefficient of variation (GCV \%); G.B: Glycine betaine; G.Y/P: Grain yield/plant; GCV\%: Genotypic coefficient of variance percentage; GMP: Geometrical mean productivity; GYP: Mean yield under normal conditions; GYS: Mean yield under salinity conditions; L1: Local wheat cultivar (Sakha 8); L2: Mutant 1; L3: Mutant 2; L4: Mutant 3; L5: Mutant 4; L6: Mutant 5; L7: Mutant 6; MP: Mean productivity; N: Normal conditions; No. of F.G/P: Number of filled grains/panicle; O.P: Osmotic pressure, osmotic adjustment; P.C: Proline content; P.H: Plant height; PCV\%: Phenotypic coefficient of variance percentage; S: Salinity treatment; SSI: Salinity susceptibility index; STI: Salinity tolerance index; T.C: Trehalose content; YI: Yield index; YI: Yield index; YR: Yield reduction ratio; YSI: Yield stability index
\end{abstract}

\section{Acknowledgements}

Not applicable.

\section{Authors' contributions}

ABAEM: Done the part on plant breeding which included agriculture and statistical analysis and reviewed the full paper (50\% contribution). HFI: Done the part of molecular markers and reviewed the full paper (50\% contribution). Both authors read, written, and approved the final manuscript.

\section{Funding}

Not applicable.

\section{Availability of data and materials}

The datasets used and/or analyzed during the current study are available from the corresponding author on reasonable request.

\section{Ethics approval and consent to participate}

Not applicable.

\section{Consent for publication}

Not applicable.

\section{Competing interests}

The authors declare that they have no competing interests.

Received: 30 March 2020 Accepted: 8 June 2020

Published online: 02 July 2020

\section{References}

Abdel Sattar AA, El-Mouhamady AA (2012) Genetic analysis and molecular markers for yield and its components in faba bean (Vicia Faba L.). Aust J Basic Appl Sci 6:458-466

Abou El-Nasr THS, Ibrahim MM, Aboud KA, El-Enany MAM (2013) Assessment of genetic variability for three coriander (Coriandrum sativum L.) cultivars grown in Egypt, using morphological characters essential oil composition and ISSR markers. Wor App Sci J25:839-849. https://doi.org/10.5829/idosi.wasj.2013.25. 06.13349

Al-Ashkar I, Alderfasi A, El-Hendawy S, Al-Suhaibani N, El-Kafafi S, Seleiman MF (2019) Detecting salt tolerance in doubled haploid wheat lines. Agronomy 9: 1-24. https://doi.org/10.3390/agronomy9040211

Al-Khaishany MY, Al-Qurainy FH, Alaraidh IA, Barakat MN, Elshafei AA, Siddiqui MH, Alamri SA, Ali HM, Alsahli AA, Alzahrani SM, Ishfaq M (2018) Genetic variation of wheat for salt tolerance based on physiological and agronomic traits. Int J Agric Biol 20:2853-2861

Al-Kordy MA, Ibrahim HM, El-Mouhamady AA, Abdel-Rahman HM (2019) Genetic stability analysis and molecular depiction in elite entries of rice (Oryza Sativa L.). Bull Nat Res Cen 43:1-15

Al-Naggar AMM, Sabry SRS, Atta MMM, Abd El-Aleem OM (2015) Effects of salinity on performance, heritability, selection gain and correlations in wheat (Triticum aestivium L). Doubled Haploids. Sci Agri 10:70-38

Balla K, Rakszegi M, Li ZG, Békés F, Bencze S, Veisz O (2011) Quality of winter wheat in relation to heat and drought shock after anthesis. Czech J Food Sci 29:117-128

Bates LS, Waldren RP, Teare ID (1973) Rapid determination of free proline for water-stress studies. Plant Soil 39:205-207

Bouslama M, Schapaugh WT (1984) Stress tolerance in soybean. Part 1: evaluation of three screening techniques for heat and drought tolerance. Crop Sci 24: 933-937

Burton GW, Devane EM (1953) Estimating heritability in tall fescue (Festuca arundinacea) from replicated clonal material. Agron J 45:478-481. https://doi, org/10.2134/agronj1953.00021962004500100005x

Chandrawat KS, Baig KS, Hashmi S, Sarang DH, Kumar A, Dumai PK (2017) Study on genetic variability, heritability and genetic advance in soybean. int J Pure App Bio sci 5: 57-63DOl: https://doi.org/10.18782/2320-7051.2592

Chen L, Huang L, Min D, Phillips A, Wang S, Madgwick PJ, Parry MAJ, Hu YG (2012) Development and characterization of a new tilling population of common bread wheat (Triticum aestivum L.). PLoS One 7:1-11

Darwish MAH, Fares WM, Eman HMA (2017) Evaluation of some bread wheat genotypes under saline soil conditions using tolerance indices and multivariate analysis. J Plant Prod Mansoura Univ 8:1383-1394

El-Demardash IS, El-Mouhamady AA, Abdel-Rahman HM, Elewa TA, Aboud KA (2017) Using gamma rays for improving water deficit tolerance in rice. Cur Sci Int 6:321-327

Eldessouky SEl, Heiba SAA, El-Mouhamady AA, Abdel-Tawab YM (2016) DNA fingerprinting and half diallel analysis of some rice genotypes under water deficit conditions. Res J Pharm, Biol Chem Sci 7:985-997

El-Keredy MS, Draz AE, Ragab AY, Abdallah AA, El-Mouhamady AA (2003) Combining ability for some quantitative characters in rice (Oryza sativa L.) under normal and saline soil conditions. The tenth conf of agro Octo Suez Canal Univ El-Irish Egypt 9:7-10

El-Mouhamady AA (2003) Breeding studies for salt tolerance in rice. Tan Uni.Kaffsheikh Agri Egypt

El-Mouhamady AA (2009) Breeding for drought tolerance in rice. PhD Thesis. Fac Agric Kaf Shei Univ Egypt

El-Mouhamady AA, Abdel-Rahman HM, Elewa TA, Aboud KA (2017) Molecular characterization and stability analysis for yield and its components traits in soybean (Glycine max L.). Int J Curr Microbiol App Sci 6:1835-1857

El-Mouhamady AA, Abdel-Rahman HM, Rizkalla AA, El-Metwally MA (2019) Assessment of water stress tolerance in wheat genotypes based on half diallel analysis and DNA fingerprinting. Pak J Biol Sci 22:103-116

El-Mouhamady AA, Amer Kh A, Ragab AY (2012a) Development of salinity tolerance in some genotypes of barley using line $\mathrm{X}$ tester analysis and some techniques of biotechnology. J Appl Sci Res 8:972-982

El-Mouhamady AA, El-Ashary ZM, Mohamed Fl, Elewa TA, Aboud KA (2016) Study the effect of water stress conditions on some genotypes of bread wheat (Triticum aestivum L.) based on morphological, physiological traits and DNA fingerprinting. RJPBCS 5:2065-2077

El-Mouhamady AA, El-Demardash IS, Aboud KA (2010) Biochemical and molecular genetic studies on rice tolerance to salinity. J Ame Sci 6:521-535

El-Mouhamady AA, El-Ekhtyar AM, El-Demardash IS (2012c) Molecular markers linked to some traits in rice. J Appl Sci Res 8:2689-2699

El-Mouhamady AA, El-Ekhtyar AM, Zayed BA (2011) Molecular genetic studies on sterility and fertility traits in rice under Egyptian conditions. Fac Sci Zag Uni 6Th Envir Conf:59-68

El-Mouhamady AA, Elewa TA, Aboud KA (2014b) Study the genetic mode of action responsible for germination seeds of oats (Avena sativa) under low and high levels of temperatures. Cur Sci Int 3:341-351

El-Mouhamady AA, El-Metwally MA (2020) Appreciation of genetic parameters and molecular characterization in some promising accessions of soybean (Glycine max L.). Pak J Biol Sci 23:425-438

El-Mouhamady AA, El-Seidy EH, Aboud KA (2012b) Identification of a molecular markers linked to drought tolerance in some genotypes of barley. Aust J Basic Appl Sci 6:196-204 
El-Mouhamady AA, El-Seidy EH, El-Ekhtyar AM, Elewa TA (2014c) Molecular markers and physiological traits linked to salinity tolerance in rice. Int J Aca Res Part A 6:195-205

El-Mouhamady AA, El-Seidy EH, Elewa TA (2014d) Using molecular markers to study mechanics responsible for drought tolerance in some genotypes of sorghum. Int J Curr Microbiol App Sci 3: 481-491

El-Mouhamady AA, Habouh MAF (2019) Genetic improvement of some rice genotypes for salinity tolerance using generation mean analysis. Cu Sci Int 8: 321-348

El-Mouhamady AA, Rady MR, El-Seidy EH (2014a) Assessment of genetic variability for six lines of wheat using physiological traits and molecular markers technique under normal irrigation and water stress conditions. W Appl Sci J 29:506-516

El-Seidy EH, El-Mouhamady AA, Aboud KA (2013) Studies on the modifications of gene expression which responsible for salinity tolerance in some genotypes of wheat. Int J Aca Res Part A 5:23-32

Esmail RM, Abdel Sattar AA, Abdel-samea NA, El-Mouhamady AA, Abdelgany EM, Fathallaha FB (2016) Assessment of genetic parameters and drought tolerance indices in maize diallel crosses. Res J Pharm, Biol Chem Sci 7 : 2409-2428

Fernandez GCJ (1992) Effective selection criteria for assessing plant stress tolerance. Proc Sym Taiw 25:257-270

Fischer RA, Maurer R (1978) Drought resistance in spring wheat cultivars. I Grain yield response. Aust J Agric Res 29:897-907

Gadallah MA, Milad SN, Mabrook YM, Abo Yossef AY, Gouda MA (2017) Evaluation of some Egyptian bread wheat (Triticum aestivium) cultivars under salinity stress. Alex Sci Exch J 38:259-270

Gavuzzi P, Rizza F, Palumbo M, Campaline RG, Ricciardi GL, Borghi B (1997) Evaluation of field and laboratory predictors of drought and heat tolerance in winter cereals. Can J Plant Sci 77:523-531

Golestani SA, Assad MT (1998) Evaluation of four screening techniques for drought resistance and their relationship to yield reduction ratio in wheat. Euphyt-ica 103:293-299

Gomez KA, Gomez AA (1984) Statistical procedures for agricultural research, 2th edn. Wiley, New York, p 680

Goseve NA (1960) Some methods in studying plant water relation. Leningrd Acadd of Sci USSR

Grieve CM, Grattan SR (1983) Rapid assay for determination of water soluble quaternary ammonium compounds. Plant Soil 70:303-307

Hamawaki OT, De Sousa LB, Romanato FN, Nogueira APO, Júnior CDS, Polizel AC (2012) Genetic parameters and variability in soybean genotypes. Com Sci 3:76-83

Heiba SAA, Eldessouky SEl, El-Mouhamady AA, El-Demardash IS, Abdel-Raheem AA (2016b) Use of RAPD and ISSR assays for the detection of mutation changes in wheat (Triticum aestivium L.) DNA induced by ethyl-methane sulphonate (EMS). Int J Chem Tech Res 9:42-49

Heiba SAA, El-Mouhamady AA, Eldessouky SEl, Hoda BMA, Elewa TA (2016a) Study the genetic variations related to the resistance of heavy metals toxicity in some rice genotypes using RAPD markers. Int J Curr Microbiol App Sci 5: 174-189

Hossain ABS, Sears AG, Cox TS, Paulsen GM (1990) Desiccation tolerance and its relationship to assimilate partitioning in winter wheat. Crop Sci 30:622-627

Jaccard P (1908) Nouvelles researchers Sur La Istribution Lorale. Bull Soc Vaud Sci Nat 44:223-270

Johnson HW, Robinson HF, Comstock RE (1955) Estimates of genetic and environmental variability in soybeans. Agron J 47:314-318 https://doi.org/10. 2134/agronj1955.00021962004700070009x

Khatab IA, El-Mouhamady AA, Abdel-Rahman HM, Farid MA, El-Demardash IS (2017) Agro-morphological and molecular characterization of sorghum (Sorghum Vulgare L.) for water stress tolerance. Inter J Cur Res Bio Plant Biol 4:37-55

Khatab IA, El-Mouhamady AA, Mariey SA, Elewa TA (2019) Assessment of water deficiency tolerance indices and their relation with ISSR markers in barley (Hordeum vulgare L.). Cu Sci Inte 8:83-100

Lin CS, Binns MR, Lefkovitch LP (1986) Stability analysis: where do we stand? Crop Sci 26:894-900

Ramadan WA, Abdel-Rahman HM, El-Mouhamady AA, Habouh MAF, Aboud KA (2016) Molecular genetic studies on some barley entries for drought tolerance. Int J Pha Tech Res 9:265-285

Saddiq MS, labal S, Afzal I, Ibrahim AH, Bakhtavar MA, Jahanzaib MBH, Maqbool MM (2019) Mitigation of salinity stress in wheat (Triticum aestivum L.) seedlings through physiological seed enhancement. J Plant Nutr:1-15 https://doi.org/10.1080/01904167.2019.1609509

Sahoo S, Baranda B, Nitesh (2018) Salinity tolerance in wheat. Marumegh 3:61-65

Sen A, Sarsu F (2018) Genetic diversity in sodium azide induced wheat mutants studied by SSR markers. Trak Uni J Nat Sci 19:129-135

Shoaib RM, Abdel-Samea NS, Ramadan WA, Ibrahim MM, Aboud KA (2016) Elucidation of genetic parameters among some selected genotypes of prickly oil lettuce (lactuca serriolla L.) in Egypt, using morpho-agronomic traits and RAPD markers. RJPBCS 7:1255-1264 https://www.researchgate.net/ publication/305154923

Singh NK, Balyan HS (2009) Induced mutations in bread wheat (Triticum aestivum L.) CV. 'kharchia 65 ' for reduced plant height and improve grain quality traits. Adv Biol Res 3:215-221

Tawfik RS, El-Mouhamady AA (2019) Molecular genetic studies on abiotic stress resistance in sorghum entries through using half diallel analysis and intersimple sequence repeat (ISSR) markers. Bull Nati Res Cen 43:1-17

Yassin M, Fara SA, Hossian A, Saneoka H, El Sabagh A (2019) Assessment of salinity tolerance bread wheat genotypes: using stress tolerance indices. Fresenius Environ Bull 28:4199-4217

Zian AH, El-Demardash IS, El-Mouhamady AA, El E (2013) Studies the resistance of lupine for (Fusarium oxysporum f. sp Lupini) through molecular genetic technique. W Appl Sci J 26:1064-1069

Zietkiewicz E, Rafalski A, Labuda D (1994) Genome fingerprinting by simple sequence repeats (SSR)-anchored polymerase chain reaction amplification. Genomics 20:176-183

\section{Publisher's Note}

Springer Nature remains neutral with regard to jurisdictional claims in published maps and institutional affiliations.

\section{Submit your manuscript to a SpringerOpen ${ }^{\circ}$ journal and benefit from:}

- Convenient online submission

- Rigorous peer review

- Open access: articles freely available online

- High visibility within the field

- Retaining the copyright to your article

Submit your next manuscript at $>$ springeropen.com 